\title{
Ruxolitinib sensitizes ovarian cancer to reduced dose Taxol, limits tumor growth and improves survival in immune competent mice
}

\author{
Patrick M. Reeves ${ }^{1}$, Mojgan A. Abbaslou ${ }^{1}$, Farah R.W. Kools ${ }^{1}$, Kritchai \\ Vutipongsatorn $^{1}$, Xiaoyun Tong $^{1}$, Christina Gavegnano ${ }^{2}$, Raymond F. Schinazi ${ }^{2}$ \\ and Mark C. Poznansky ${ }^{1}$

\begin{abstract}
${ }^{1}$ Vaccine and Immunotherapy Center, Division of Infectious Diseases, Department of Medicine, Massachusetts General Hospital, Boston, MA 02129, USA

${ }^{2}$ Center for AIDS Research, Laboratory of Biochemical Pharmacology, Department of Pediatrics, Emory University School of Medicine, Atlanta, GA 30322, USA

Correspondence to: Patrick M. Reeves, email: pmreeves@partners.org

Mark C. Poznansky, email: mpoznansky@partners.org

Keywords: Ruxolitinib, ovarian, Taxol, combination, immunocompetent

Received: May 04, $2017 \quad$ Accepted: July 02, $2017 \quad$ Published: October 04, 2017

Copyright: Reeves et al. This is an open-access article distributed under the terms of the Creative Commons Attribution License 3.0 (CC BY 3.0), which permits unrestricted use, distribution, and reproduction in any medium, provided the original author and source are credited.
\end{abstract}

\section{ABSTRACT}

Background: Chemotherapy initially reduces the tumor burden in patients with ovarian cancer. However, tumors recur in over $70 \%$ of patients, creating the need for novel therapeutic approaches.

Methods: We evaluated Ruxolitinib, an FDA-approved JAK 1/2 kinase inhibitor, as a potential adjunctive therapy for use with low-dose Taxol (Paclitaxel) by assessing the impact on in vitro proliferation and colony formation of ID8 cells or human TOV112D ovarian cancer cells, as well as flow cytometric measurement of surface markers associated with cellular stress and stemness by ID8 cells. The syngeneic ID 8 murine model of ovarian cancer was used to assess the impact of Ruxolitinib and Taxol, individually and in combination, on tumor initiation and growth, as well as capacity to extend survival.

Results: Ruxolitinib ( $\leq 10 \mu \mathrm{M})$ sensitized both ID8 and TOV-112D cells to low concentrations of Taxol ( $\leq 5 \mathrm{nM}$ ), limiting cell proliferation and colony formation in vitro. Mechanistically, we demonstrated that Taxol induced expression of stress and stemness markers including GRP78 and CD133 was significantly reduced by addition of Ruxolitinib. Finally, we demonstrated that a single administration of a low-dose of Taxol (10 mg/ Kg) together with daily Ruxolitinib $(30 \mathrm{mg} / \mathrm{Kg}$; which is equivalent to plasma concentrations of $\sim 0.01 \mu \mathrm{M}$ steady-state) limited ID8 tumor growth in vivo and significantly extended median survival up to $53.5 \%$ (median $70 \mathrm{v} 107.5$ days) as compared to control mice.

Conclusion: Together, these data support the use of Ruxolitinib in combination with low-dose Taxol as a therapeutic approach with the potential for improved efficacy and reduced side effects for patients with recurrent ovarian cancer.

\section{INTRODUCTION}

Many patients with ovarian cancer are diagnosed late in disease progression (stage III and IV), resulting in a 5 -year survival rate of less than $30 \%[1,2]$. As a result of this, ovarian cancer is the fifth most lethal cancer for women $[2,3]$. Standard treatment for ovarian cancer frequently involves tumor reduction surgery together with chemotherapy, which can significantly reduce tumor burden and extend survival. However, the 
majority of patients who receive traditional surgery and chemotherapy relapse less than 18 months after initial diagnosis. The high morbidity and mortality in those with rapid relapse highlights the need for additional robust therapies to complement surgical removal of tumor masses $[2,3]$. Numerous approaches using targeted therapies to limit tumor growth and neovascularization remain under evaluation including Bevacizumab, an antivascular endothelial growth factor (VEGF) antibody, and Erlotinib, a small molecule inhibitor of epidermal growth factor receptor (EGFR) [4-6]. Another approach seeks to enhance the sensitivity of cancer cells to chemotherapy through the use of small molecules targeting essential signal transducing molecules such as AKT and Aurora kinases [7, 8]. Here, using both the TOV-112D human cell line and the immunocompetent murine ID8 model, we assessed the impact on ovarian cancer of Ruxolitinib (Ruxo, Jakafi), an FDA-approved, orally bioavailable small molecule inhibitor of Janus Kinases 1/2 (JAK 1/2), delivered alone or in combination with low-dose Paclitaxel (Taxol) chemotherapy.

JAKs are cytosolic tyrosine kinases linked to signaling from cell membrane receptors including G-protein coupled receptors and cytokine receptors that activate signal transducer and activator of transcription (STAT) family transcription factors to alter gene expression [9]. Tumors can express stress response genes as a result of hypoxia, mechanical tension, and toxins (including chemotherapeutic agents) which through JAK/ STAT signaling and expression of stress-response genes is also associated with stemcell-like properties or stemness [10]. Several STAT-dependent stress response genes including GRP78, CD133, SCA-1 (CD44), and CD117 are upregulated in ovarian cancer [11-14]. This increased expression of stress-response and stem cell markers is associated with drug resistance, tumor initiation and progression, and metastasis in human breast and ovarian cancer [12]. Ovarian cancer exploits a variety of resistance mechanisms including target protein or compensatory mutations, expression of drug pumps, induction of stressresponse genes, adoption of stem cell characteristics, immune evasion through recruitment of regulatory T-cells (T-regs), and chronic interferon signaling [15, 16]. Importantly, previous reports indicate that Taxol can induce expression of STAT-dependent stress markers, while inhibition of the JAK/STAT pathway reduces the expression of stress markers and enhances sensitivity of cancer cells to chemotherapy, including hepatocellular and ovarian cancers [17-19]. The JAK 1/2 inhibitor Ruxo, initially approved to treat myelofibrosis, has shown potential utility in HIV, arthritis, and is currently under evaluation in combination with chemotherapy (e.g. Paclitaxel, Capecitabine) for the treatment of pancreatic cancer, breast cancer, and a recently announced trial for ovarian cancer [20-25]. These findings are likely due to the immunomodulatory properties of Ruxo, which confers potent, specific inhibition of IL- $6, \mathrm{TNF}-\alpha, \mathrm{IL}-1 \alpha / \beta, \mathrm{CRP}$, and other pro-inflammatory/immunoregulatory cytokines in vivo, which indirectly alter the systemic milieu for various pro-inflammatory indications, resulting in cessation of clinical manifestation of symptoms [26, 27]. It is possible that blockade of JAK-STAT signaling in the context of ovarian cancer, when applied at concentrations that allow for block of pro-cancer signaling while maintaining functional adaptive immunity, could result in additional benefit versus traditional mono-therapies alone.

Here, we show that treatment of murine and human ovarian cancer cells with a combination of Ruxo and low-dose Taxol limits ovarian cancer cell growth and colony formation in vitro. Taxol induced the expression of markers associated with cellular stress responses and stemness, GRP78, CD133, SCA-1, and CD117, and coadministration of Ruxo mitigated some of these effects. Additionally, using the C57BL/6 ID8 syngeneic murine model, we demonstrate that Ruxo augments the capacity of low-dose Taxol therapy to limit tumor growth and extend survival in immunocompetent animals. Together these data suggest that Ruxo in combination with low-dose Taxol chemotherapy may improve outcomes for patients with ovarian cancer, in part through its impact on mitigating cancer cell stress responses to the chemotherapeutic agent.

\section{RESULTS}

\section{Ruxo in combination with low-dose Taxol in vitro limits ID8 and TOV-112D cell proliferation}

To test the capacity of Ruxo to sensitize cells to Taxol, we assessed the impact of each compound individually on cell proliferation using ID8 murine and TOV-112D human ovarian cancer (Supplementary Figure 1). The selected concentrations of Ruxo, 5-10 $\mu \mathrm{M}$, had limited or no impact on cell proliferation and represent concentrations at or above all $\mathrm{C}_{\text {max }}$ and steady-state plasma concentrations for this drug for all FDA approved doses in humans $[26,27]$. The Taxol concentrations employed, 1-5 nM, limited proliferation 10-50\%, allowing enhanced sensitivity by Ruxo to be observed. In patients, standard dosing of Taxol for ovarian and other cancers utilizes $135-250 \mathrm{mg} / \mathrm{m}^{2}$, and reduced doses from $60-80 \mathrm{mg} / \mathrm{m}^{2}$. Studies with lung and ovarian cancer patients determined that a 24-h i.v. infusion of Taxol $135 \mathrm{mg} / \mathrm{m}$ or $250 \mathrm{mg} / \mathrm{m}$ results in an average plasma steady state concentration of $320 \mathrm{nM}$ and $850 \mathrm{nM}$ respectively [28, 29]. Thus, Taxol concentrations used in this study are 64-850 fold less, and represent a low dose of Taxol.

The proliferation of ID8 cells was not affected by Ruxo treatment alone even at concentrations as high as $10 \mu \mathrm{M}$. Taxol at concentrations as low as $5 \mathrm{nM}$ proved sufficient to inhibit ID8 cell proliferation by $40-50 \%$ (Figure 1, Supplementary Figure 1). Co-incubation with both Ruxo $(10 \mu \mathrm{M})$ and Taxol $(5 \mathrm{nM})$ further reduced ID8 
cell proliferation by as much as $90 \%$ (Figure $1 \mathrm{~A}$ ). In TOV$112 \mathrm{D}$ human ovarian cancer cells, Ruxo $(5 \mu \mathrm{M})$ treatment alone did not significantly reduce cell growth, whereas low-doses of Taxol ( $1 \mathrm{nM}$ ) reduced proliferation by $22 \%$ (Figure 1B, Supplementary Figure 1). The combination of Ruxo $(5 \mu \mathrm{M})$ and Taxol $(1 \mathrm{nM})$ reduced cell growth by $45 \%$ (Figure 1B). Thus, in both murine ID8 cells and human TOV-112D cells, Ruxo sensitized cells to treatment with Taxol in vitro.

Recent reports indicate that for combination drug therapy, the order in which drugs are administered can significantly alter efficacy [30-32]. To test this possibility with Ruxo and Taxol, ID8 or TOV-112D cells were initially incubated in the presence of either Ruxo or carrier (DMSO) for $96 \mathrm{hr}$, at which time equal numbers of viable cells were re-plated and treated with Ruxo, Taxol, or a combination of both drugs. As shown in Figure 1C, pretreatment of ID8 cells with carrier followed by Taxol at $5 \mathrm{nM}$ reduced cell proliferation by $50 \%$, whereas pretreatment with Ruxo followed by Taxol reduced cell growth by $75 \%$. In addition, pre-treatment with carrier or Ruxo followed by incubation with both Ruxo and Taxol reduced proliferation by $84 \%$ and $90 \%$, respectively (Figure 1C). Pretreatment of TOV-112D cells with carrier followed by incubation with Taxol reduced proliferation by $22 \%$, while Ruxo pretreatment prior to Taxol did not reduce cell growth. However, pretreatment with Ruxo followed by Ruxo, Taxol, or both reduced proliferation by $40 \%, 45 \%$, and $48 \%$ respectively. Together these data indicate that pre-incubation with Ruxo does not improve the effects of subsequent incubation with Taxol or Ruxo and Taxol together.

\section{Ruxo together with low dose Taxol limits tumor cell colony formation in vitro}

To further characterize the effect of treatment with Ruxo and Taxol on cell proliferation, soft-agar colony formation assays were carried out with ID8 and TOV-112D cells. Notably ID8 cells form smaller colonies $(\geq 2 \mathrm{~mm})$ than TOV-112D cells which form larger colonies $(\geq 5 \mathrm{~mm})$ and large clusters $(\geq 15 \mathrm{~mm})$. Treatment of ID8 cells with Ruxo $(10$ or $1 \mu \mathrm{M})$ or Taxol $(0.015 \mu \mathrm{M}$ or $0.005 \mu \mathrm{M})$ alone reduced colony formation in a dose-dependent manner by 55-95\% (Figure 2A). Co-incubation with both Ruxo and Taxol further reduced colony formation in a dose-dependent manner, demonstrating that co-incubation with both drugs is more effective than either drug alone (Figure 2A). In TOV-112D cells, Ruxo at $2.5 \mu \mathrm{M}$ or Taxol at $1 \mathrm{nM}$ alone reduced colony formation by $16 \%$ and $23 \%$ respectively, whereas co-incubation with Ruxo and Taxol reduced colony formation by 53\% (Figure 2B). Together, these data demonstrate Ruxo and low-dose Taxol delivered in combination limit the capacity of mouse and human ovarian cancer cells to form colonies in soft agar.

\section{Ruxo limits Taxol induced expression of stress/ stem cell markers in ID8 cells in vitro}

To determine the effects of Ruxo and Taxol on the JAK/STAT induced stemness markers, surface expression levels of GRP78, CD133, SCA-1, and CD117, were assessed by flow cytometry. Changes in expression were measured in ID8 cells. Baseline levels, normalized to unlabeled cells, were assigned a value of $0 \%$, whereas levels seen in cells treated with Taxol were assigned a value of $100 \%$. Treatment with Taxol alone increased surface levels of GRP78, CD133, SCA-1, and CD117 relative to the untreated control by between 2 and 25 fold depending on the marker, whereas treatment with Ruxo produced at most modest reductions $(0-15 \%)$ in surface levels of these markers (Figure 3). In contrast, treatment of ID8 cells with both Ruxo and Taxol significantly reduced the levels of GRP-78 (50\%) and CD133 (30\%) compared to Taxol treatment alone, levels of SCA-1 and CD117 were modestly reduced $(<15 \%)$ (Figure $3)$. These data indicate that treatment with Taxol increases the surface expression of markers associated with the cellular stress response and stemness, and that co-administration of Ruxo can limit this effect.

\section{Ruxo and low-dose Taxol limit ID8 tumor growth in vivo}

In view of the in vitro findings demonstrating that 1) Ruxo pretreatment confers potent block of ovarian cell proliferation, 2) addition of Ruxo and Taxol limit the capacity of ovarian cancer cells to form colonies, and 3) Ruxo mitigates the Taxol-induced up-regulation of procancer markers (SCA-1, CD117), we sought to understand how these effects impact ovarian cancer in vivo. We assessed the impact of Ruxo and low-dose Taxol, delivered alone or in combination, on the capacity of ID8 cells to form tumors in vivo in immune competent mice. ID8 cells modified to express firefly luciferase (ID8-Luc) were first cultured in vitro with Ruxo $10 \mu \mathrm{M}$, Taxol $5 \mathrm{nM}$, both Ruxo and low-dose Taxol, or carrier (DMSO). Then, either $2.5 \mathrm{x}$ $10^{5}$ or $2.5 \times 10^{6}$ viable ID8-Luc cells from each pre-treatment group were injected intraperitoneally into C57BL/6 mice. Animals receiving post-tumor cell injection treatment were then administered Ruxo QD (30 mg/Kg) beginning 3 days post inoculation, whereas control (carrier only) animals were left untreated. Tumor size was monitored at weekly intervals for 5 weeks by in vivo imaging (IVIS) of luciferase signal. After this time, no further imaging was conducted and animals were monitored for survival.

All cell pre-treatment conditions significantly ( $\mathrm{p} \leq$ 0.0003 ) reduced tumor burden at 5 weeks as compared to carrier-treated control cells (Figure 4A and 4B). In animals injected with $2.5 \times 10^{5}$ cells, tumors showed significantly less growth for all conditions relative to the control, with the Ruxo-Taxol group showing the greatest reduction (3.6 fold) in growth (Figure 4A). In animals receiving $2.5 \times 10^{6}$ cells, the Ruxo pre-treatment group showed less 
A

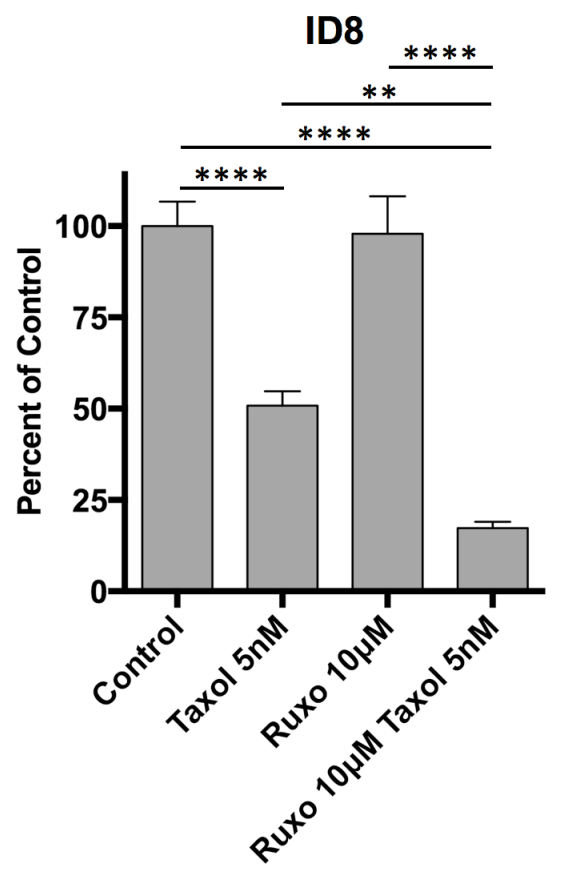

C

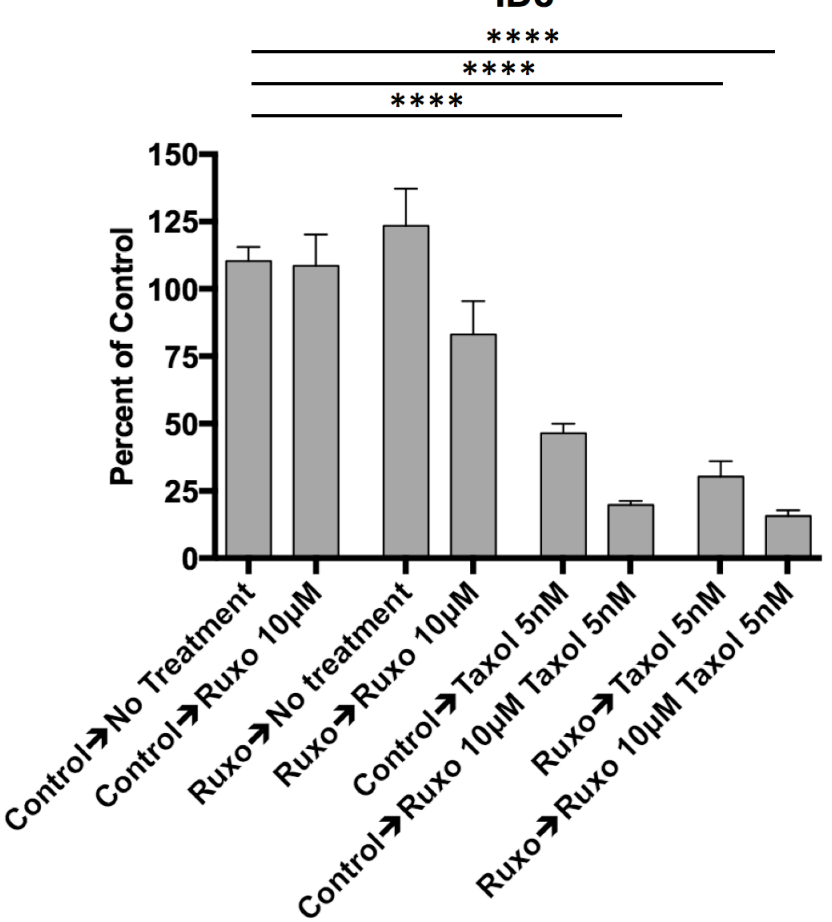

B

TOV-112D

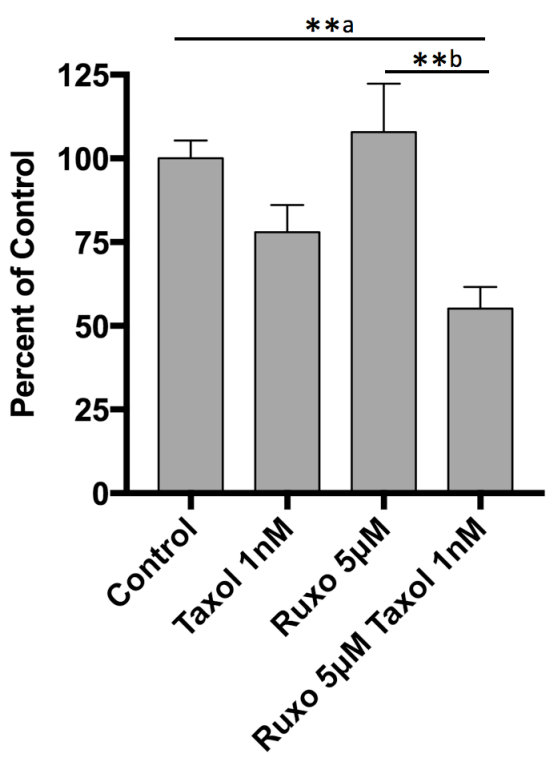

D

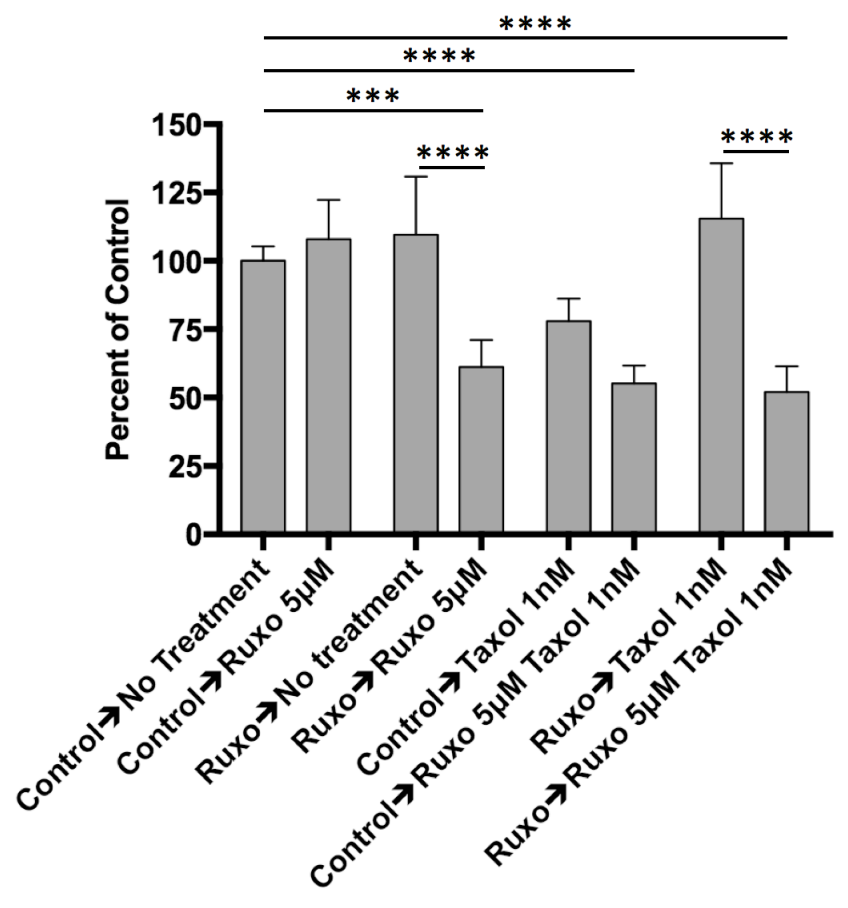

Figure 1: Ruxo and Taxol limit ID8 and TOV-112D cell proliferation. (A) ID8 cells grown for 72 hours treated with carrier, $10 \mu \mathrm{M}$ Ruxo, $5 \mathrm{nM}$ Taxol, or both, measured in triplicate ${ }^{* *} \mathrm{p}=0.0041,{ }^{* * * * *} \mathrm{p}<0.0001$, from 4 experiments) (B) TOV-112D cells grown for 96 hours treated with carrier, $5 \mu \mathrm{M}$ Ruxo, $1 \mathrm{nM}$ Taxol, or both, measured in triplicate ( ${ }^{* *} \mathrm{a}=0.0097,{ }^{* *} \mathrm{~b} \mathrm{p}=0.0020$, from 4 experiments). (C) ID8 cells were first exposed to carrier or Ruxo $10 \mu \mathrm{M}$ for 72 hours, harvested, and re-plated in triplicate in media containing carrier, $10 \mu \mathrm{M}$ Ruxo, $5 \mathrm{nM}$ Taxol, or both for a further 72 hours. ${ }^{* *} \mathrm{p}=0.0049,{ }^{* * * *} \mathrm{p}<0.0001$, from 3 experiments (D) TOV-112D cells were first exposed to carrier or Ruxo $5 \mu \mathrm{M}$ for 96 hours, harvested, and re-plated in triplicate in media containing carrier, $5 \mu \mathrm{M}$ Ruxo, $1 \mathrm{nM}$ Taxol, or both for an additional 96 hours. $\left({ }^{* * *} \mathrm{p}=0.0003,{ }^{* * * *} \mathrm{p}<0.0001\right.$, from 3 experiments). Bars represent mean, error bars SEM. For panel A \& B statistical analysis performed by one-way ANOVA followed by multiple comparisons between all groups with Bonferroni correction, in panels C \& D two-way ANOVA followed by multiple comparisons between all groups with Bonferroni correction. Line above treatment groups indicates comparison resulting in statistically significant difference. 
attenuation in growth ( $p=0.0003)$, compared to the other groups, though all showed significantly less growth than the control group (all groups $\mathrm{p}<0.0001$, Figure 4B)

In mice injected with $2.5 \times 10^{5}$ pre-treated cells, all treatments were associated with significantly increased survival relative to mice injected with control-treated cells (Figure 4C). Whereas the control group had a median survival of 85 days, the median survival for drug groups was between 1.2 and 1.8 fold longer $($ Ruxo $=132$ days, Taxol $=114$ days, Ruxo-Taxol $=150$ days, and Ruxo posttreatment $=108$ days $)($ Figure $4 \mathrm{C})$. In mice injected with
$2.5 \times 10^{6}$ cells, the control group had a median survival of 60 days and the median survival for the drug groups was 10 to $60 \%$ longer (Ruxo $=69$ days, Taxol $=99$ days, Ruxo-Taxol $=96$ days, and Ruxo post-treatment $=81$ days) (Figure 4D). The Ruxo-Taxol and Ruxo pretreatment groups showed the greatest percentage increase in survival in both animals injected with $2.5 \times 10^{5}$ and $2.5 \times$ $10^{6}$ cells. In accordance with our tumor imaging studies, Taxol alone and Ruxo plus Taxol pre-treatment groups exhibited the greatest percentage increase in survival, achieving statistical significance in the $2.5 \times 10^{6}$ groups ( $\mathrm{p}$
A
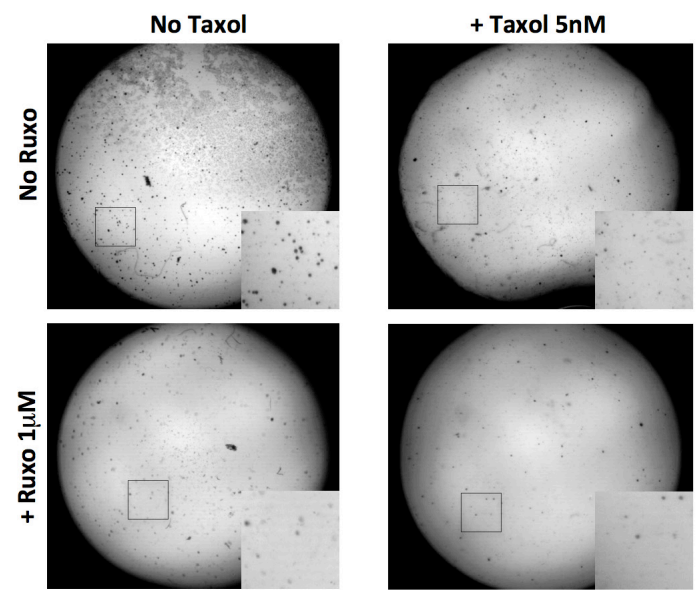

B
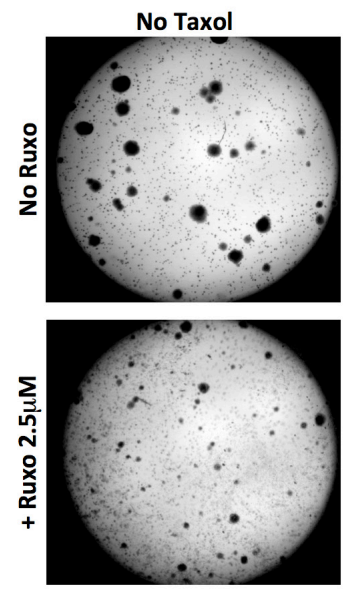
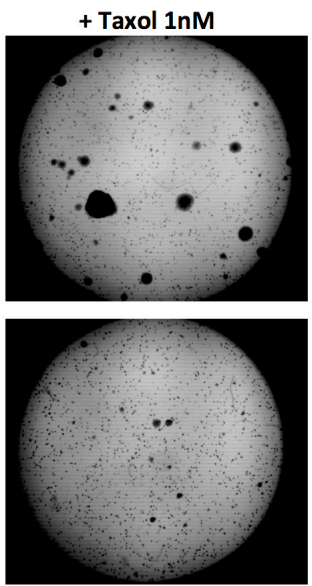

ID8
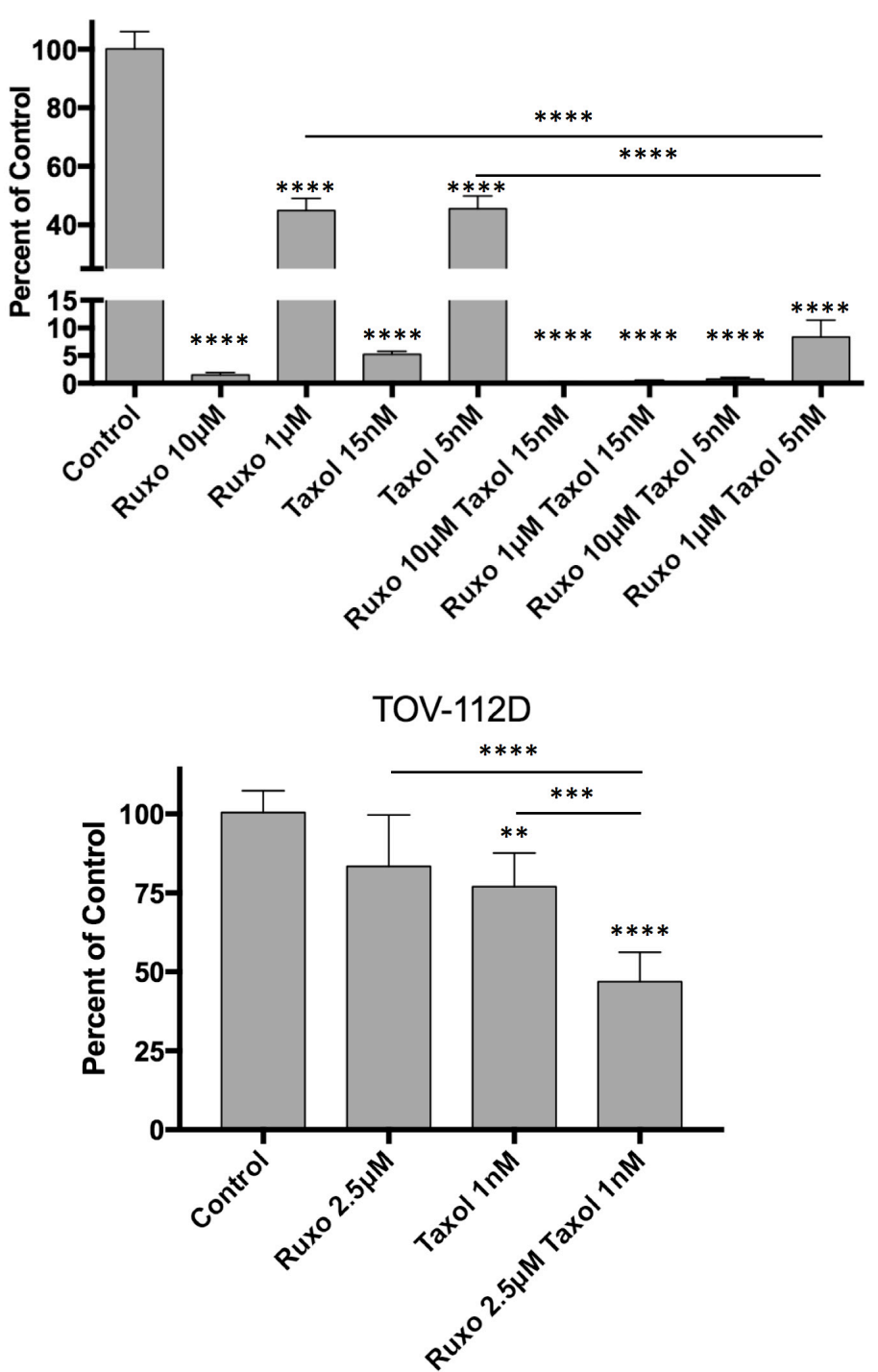

Figure 2: Ruxolitinib and Taxol limit ID8 and TOV-112D colony formation ID8. (A) or TOV-112D (B) cells were seeded in soft agar containing Ruxo or Taxol, or both. ID8 cells were treated with $10 \mu \mathrm{M}$ or $1 \mu \mathrm{M}$ Ruxo, $5 \mathrm{nM}$ or $15 \mathrm{nM}$ Taxol, or pairwise combinations of each. Regions matching 5x enlarged inset images indicated by white box. TOV-112D cells received $2.5 \mu \mathrm{M}$ Ruxo, $1 \mathrm{nM}$ Taxol, or both. Plates were incubated for 30 days for ID8 and 21 days for TOV. Crystal violet stained colonies were imaged and subsequently enumerated on the basis of size using ImageJ, counting colonies $\geq 2 \mathrm{~mm}$ for ID8 or $\geq 5 \mathrm{~mm}$ for TOV-112D. Graphs represent normalized mean of 3 wells, error bar SEM, 3 independent experiments, one-way ANOVA analysis followed by multiple comparisons between all groups with Bonferroni correction. Significance relative to control indicated directly above condition. Inter-condition comparisons indicated by line ${ }^{* *}$ $\left.\mathrm{p}=0.0055,{ }^{* * *} \mathrm{p}=0.0006,{ }^{* * * *} \mathrm{p}<0.0001\right)$. 
$=0.0017$ for both). These data indicate that Ruxo treatment alone, Ruxo in combination with Taxol, or administered daily post-inoculation, can limit tumor growth and prolong survival.

\section{Reduced doses of Ruxo and Taxol in combination extend survival in tumor-bearing mice}

To explore the therapeutic effect of Ruxo and Taxol in combination, the effects of reduced doses of either drug, alone and in combination, on tumor growth and survival were determined. We used a single administration of Taxol at a dose of $10 \mathrm{mg} / \mathrm{Kg}$ (Taxol 10), which represents approximately one third of the maximum tolerated dose

\section{GRP78}

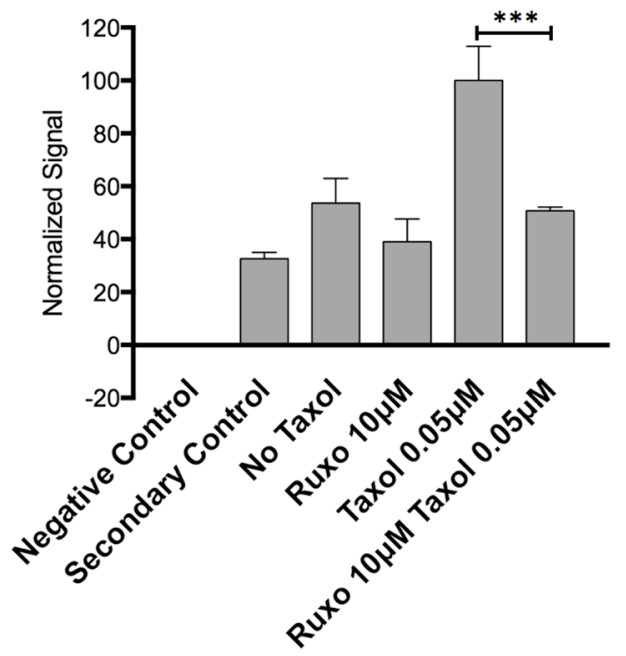

CD133

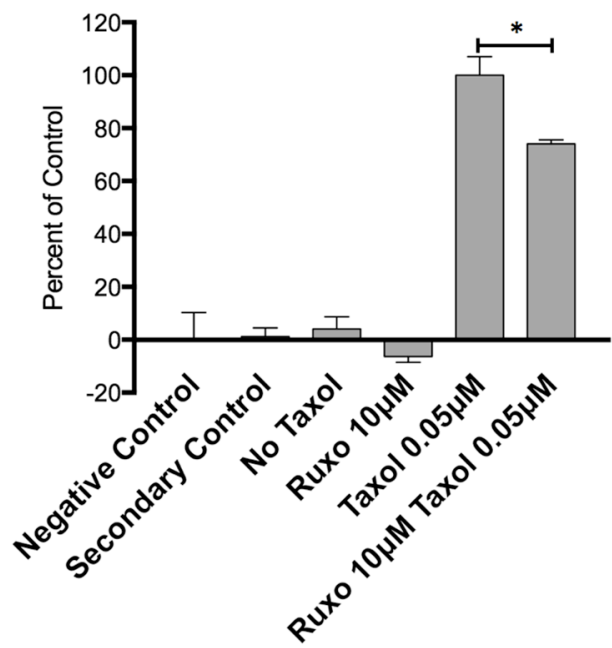

in mice and is in the metronomic range [33, 34]. We followed two different treatment schedules, altering the duration of tumor growth prior to treatment, and the order in which Ruxo and Taxol were applied (Figure 5A). In the first experiment, mice (7-8 weeks old) were injected with $5 \times 10^{6}$ ID8-Luc cells. After 14 days, tumor growth was assessed weekly for 6 weeks by IVIS measurement of luciferase signal and treatment with a single dose of Taxol followed on day 19. Daily administration of Ruxo $30 \mathrm{mg} / \mathrm{Kg} / \mathrm{d}$ (Ruxo 30), which corresponds to a human dose of $\sim 5-10 \mathrm{mg}$ BID (pharmacokinetics performed as previously described [35]), began on day 23 post tumor inoculation. We observed that single agent Ruxo 30 or Taxol 10 treatment individually did not significantly

\section{SCA-1}

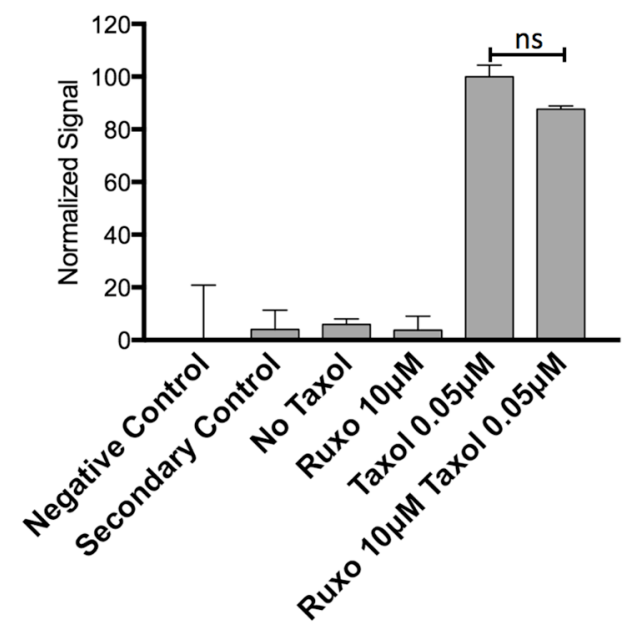

CD117

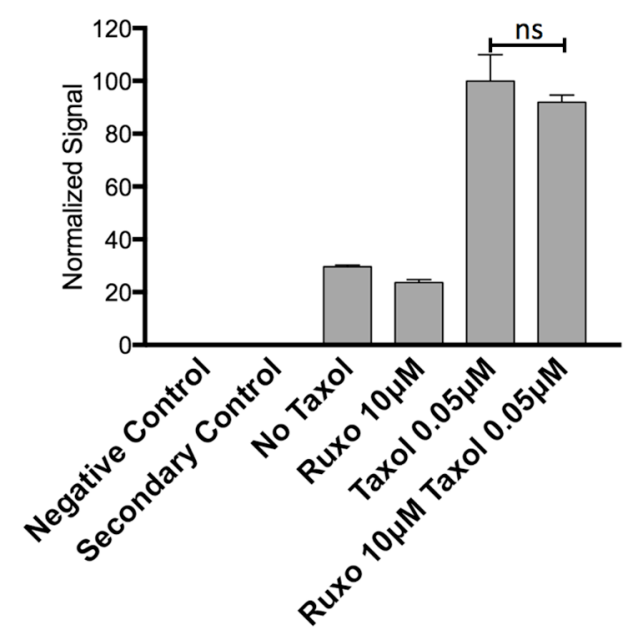

Figure 3: Effect of Ruxo and Taxol on Expression of stress and stemness associated markers ID8 cells were treated with Ruxo 10 $\mu \mathrm{M}$, Taxol $0.05 \mu \mathrm{M}$ or both for 96 hours and surface labeled with for GRP78 (A), SCA-1 (B), CD133 (C), and CD117 (D), negative controls are unlabeled and secondary control are cells labeled with secondary antibody only. Flow cytometry MFI values normalized by adjusting value of negative control (unstained cells) to 0 and Taxol $0.05 \mu \mathrm{M}$ to $100 \%$. $\left.{ }^{* * *} \mathrm{p}=0.0008,{ }^{*} \mathrm{p}=0.0244\right)$. Graphs represent normalized mean of 2 wells, error bars represent SEM, representative of 2 independent experiments, one-way ANOVA analysis followed by multiple comparisons between all groups with Bonferroni correction. 
reduce tumor growth by week 6 . However, treatment with Taxol 10 followed by Ruxo 30 did significantly reduce tumor growth as compared to control $(\mathrm{p}=0.0038)$ or as compared to single treatment with Ruxo $30(p=0.0366)$ but not Taxol $10(\mathrm{p}=0.1338)$ (Figure 5B). Survival in mice treated with Ruxo 30 or Taxol 10 individually increased to 92 and 94 days respectively, versus 70 day median survival in the control group. Treatment with Ruxo 30 and Taxol 10 resulted in a median survival of 107.5 days, a $52.5 \%$ increase as compared to control (Figure 5C). Survival was significantly increased, with respect to control, for individual treatment with either Ruxo 30 (p $=0.0343)$ or Taxol $(\mathrm{p}=0.008)$. The greatest increase in survival resulted from treatment with Taxol 10 followed by Ruxo $30(\mathrm{p}=0.0005)$. Treatment with Taxol 10 and Ruxo 30 also significantly improved survival as compared to individual treatment with Ruxo $30(\mathrm{p}=0.0018)$ or Taxol $10(\mathrm{p}=0.0037)$.

In a second experimental approach, mice (6-7 weeks old) were injected with $5 \times 10^{6}$ ID8-Luc cells. After one week, mice began treatment with either Ruxo 30/mg/Kg/d (Ruxo 30) or Ruxo 75 mg/Kg/d (Ruxo
A

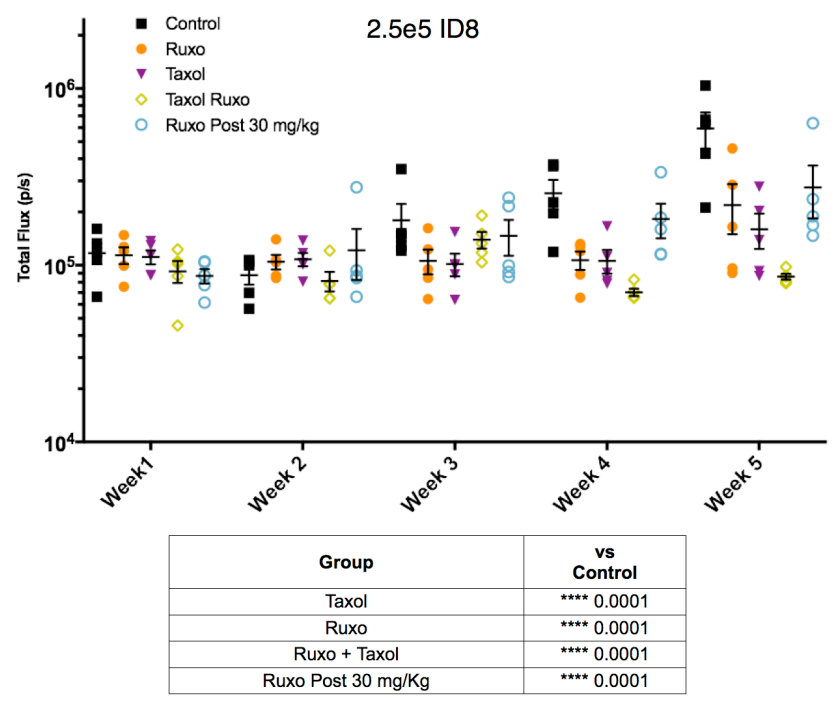

C

$2.5 \mathrm{e} 5 \mathrm{ID} 8$

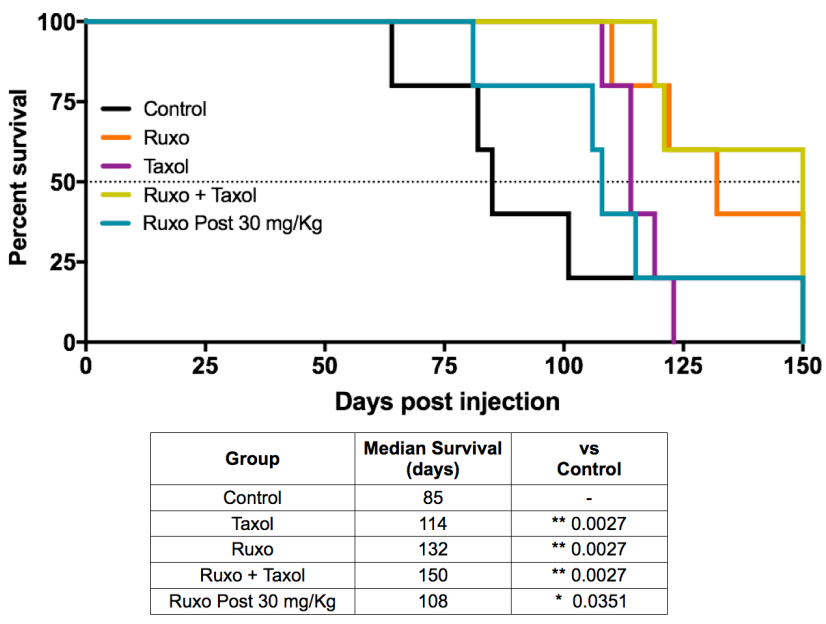

B

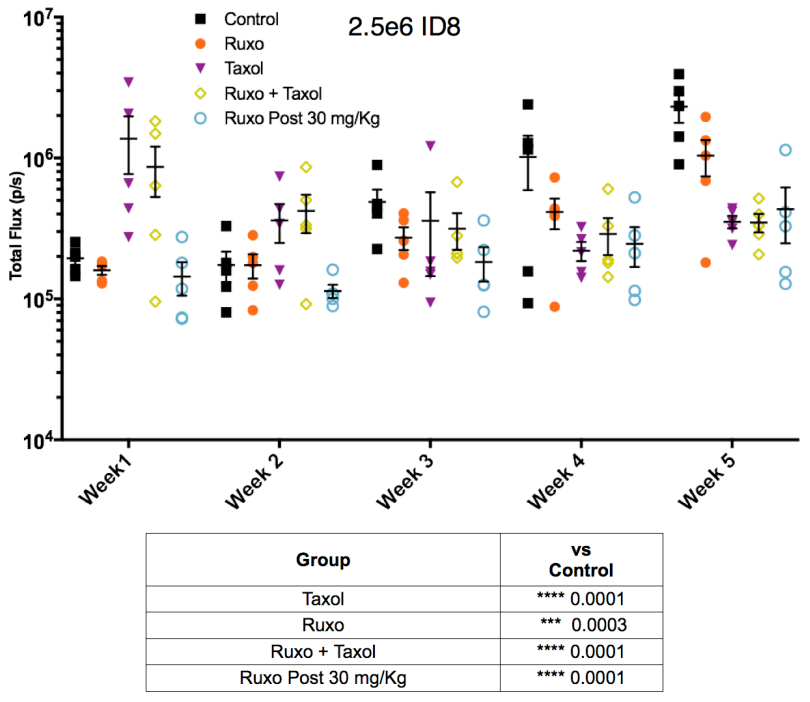

D $\quad 2.5 e 6$ ID8

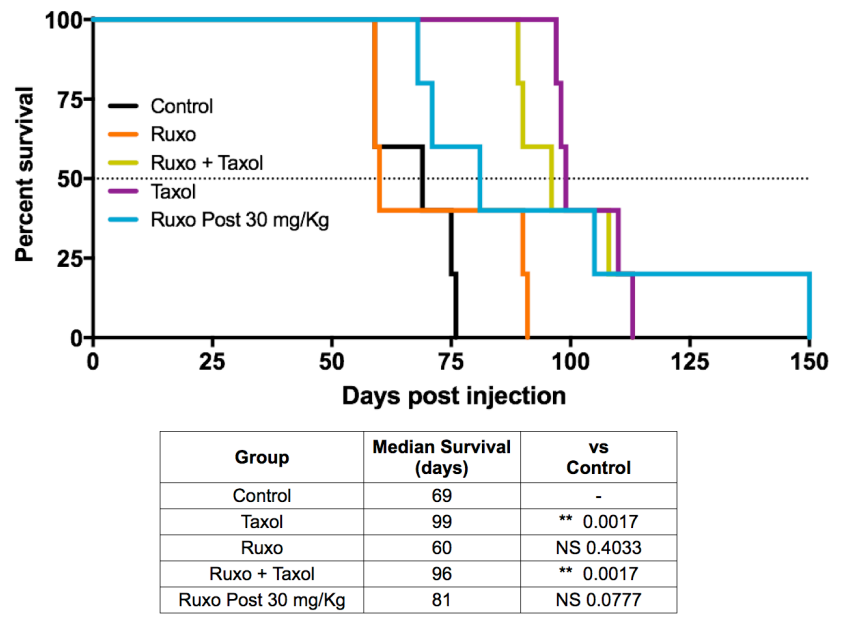

Figure 4: Effect of Ruxo and Taxol on ID8 tumor initiation and growth. ID8-Luc cells treated with either carrier (control), Taxol, Ruxo, or Ruxo and Taxol in combination and then injected into mice either with $2.5 \times 10^{6}$ (B \& D) or 2.5x 10 (A \& C) viable cells. In addition, one group received carrier treated control cells and daily Ruxo (30 mg/kg) days post injection. In panel (A \& B) tumor growth was monitored weekly for 5 weeks as measured by luciferase imaging. Data points presented with median and SEM. Tables depict analysis of week 5 luciferase signal by two-way ANOVA followed by multiple comparisons between all groups with Bonferroni correction. In panels (C \& D) survival data plotted, results of individual Mantel Cox test comparisons relative to control shown in table ( $N=5$ per group, apart from $2.5 \times 10^{5}$ control $\mathrm{N}=4$ ). 
75; which corresponds to 20-25 mg BID in humans; pharmacokinetics performed as previously described [35]). The following day, Taxol treated mice received a single administration of Taxol $10 \mathrm{mg} / \mathrm{Kg}$. After 5 weeks, neither Ruxo 30, Ruxo 75, nor Taxol 10 treatment alone significantly inhibited tumor growth compared to control.
In contrast, a single dose of Taxol 10 together with Ruxo $30(\mathrm{p}=0.0045)$ or Ruxo $75(\mathrm{p}=0.0115)$ significantly reduced tumor growth compared to control mice (Figure 5D). Treatment with Ruxo 30 and Taxol 10 significantly reduced tumor growth as compared to Ruxo 30 alone $(\mathrm{p}=$ $0.0001)$, similarly Ruxo 75 and Taxol 10 also significantly

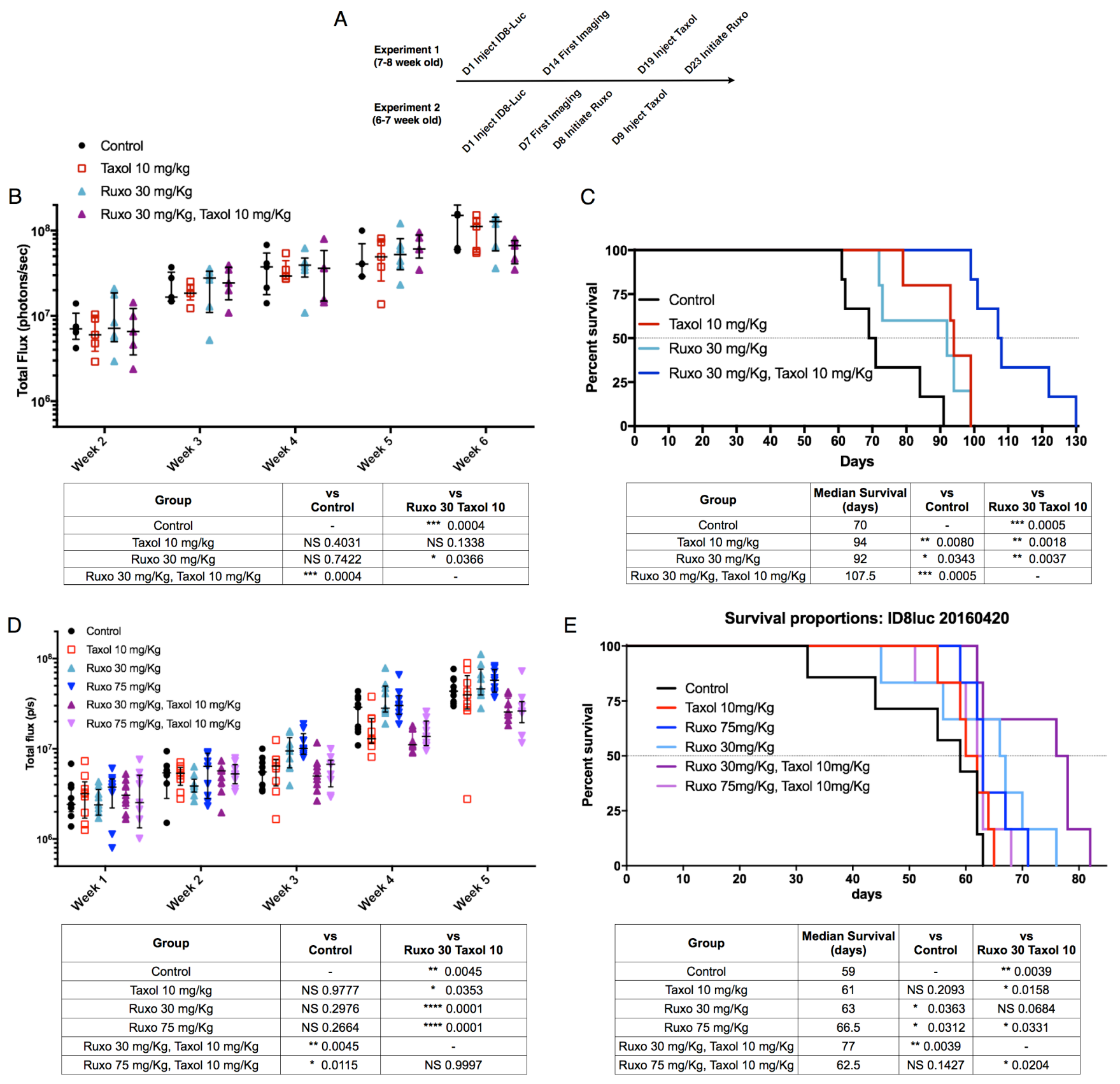

Figure 5: Impact of Ruxo and Taxol combination therapy on tumor growth and survival Mice were injected intraperitoneally with ID8-Luc cells. (A) Timeline of studies described in panels B-D. Tumor growth was monitored weekly for 5 weeks as measured by luciferase imaging. For tumor growth in B \& D, each data point is represented, with central line indicating median, upper and lower limits indicating quartile range. Results of two-way ANOVA followed by multiple comparisons between all groups with Bonferroni correction of final week values in table. Analysis of significance in survival studies determined using individual Mantel Cox test comparisons relative to control results are shown in table below graph (not significant $=\mathrm{NS})$. (B) Experiment 1 tumor growth $(\mathrm{N}=5$ Control, Taxol, Ruxo $30 \mathrm{mg} / \mathrm{kg}$ + Taxol, N=6 Ruxo $30 \mathrm{mg} / \mathrm{kg}$ ). (C) Experiment 1 survival data and comparison analysis. (N=6 per group). (D) Experiment 2 tumor growth ( $\mathrm{N}=8$ control, $\mathrm{N}=9$ per treatment group). (E) Experiment 2 survival data and comparison analysis( $\mathrm{N}=6$ per group). 
limited tumor growth as compared to Ruxo 75 alone ( $p$ $=0.0001)$. No difference in tumor growth was observed with Ruxo 30 and Taxol 10 as compared to Ruxo 75 and Taxol 10. The median survival was 59 days in the control group and treatment increased median survival to, 66.5 days for Ruxo 30 treated mice, 63 days for Ruxo 75 mice, and a single dose of Taxol 10 resulted in 61 days (Figure 5E). Combination treatment with a single dose of Taxol 10 followed by Ruxo 75 had a median survival of 62.5 days and was not significantly better than Ruxo 75 or Taxol 10 alone. Notably, the combination of Taxol 10 treatment followed by Ruxo 30 extended median survival to 77 days, a $30.5 \%$ improvement over control. Compared to Ruxo 30 alone, the increased survival in mice treated with a combination of Ruxo 30 and Taxol 10 was marginally significant $(\mathrm{p}=0.0684)$, but was significant when compared to Taxol 10 treatment alone $(p=0.0158)$ and Ruxo 75 in combination with Taxol $(p=0.0204$, Figure $5 \mathrm{E})$. Together these data indicate that a reduced dose of Ruxo, that corresponds to a human dose of 5-10 mg BID and the lowest FDA-approved dose for this agent, potentiates the effect of reduced dose Taxol. In addition, these data support the view that the combination of Ruxo 30 and a single administration of Taxol 10 is associated with a significant benefit on both tumor burden reduction and survival.

\section{DISCUSSION}

Here we demonstrate, for the first time, the use of Ruxolitinib (Ruxo), a FDA-approved JAK 1/2 inhibitor, to sensitize ovarian cancer to low-dose Taxol based chemotherapy both in vitro and in vivo in an immunocompetent orthotopic murine model. The use of small molecule inhibitors that target signaling pathways essential for cancer cell proliferation in conjunction with chemotherapy has garnered significant interest as a way to increase the efficacy of chemotherapeutic agents and limit development of resistance as compared to monotherapy. However, combination approaches can also increase the likelihood of drug toxicities and serious side effects. Previous reports have investigated Ruxo for the treatment of cancer in several animal models of head, neck, non-small cell lung carcinoma, and ovarian cancer $[17,36,37]$ and describe the immune stimulating effect of reduced dose chemotherapy, including Taxol [38-41]. In this context, our preclinical data presented here in lends supports to the utility of the combination of both of these therapeutic agents in ovarian cancer.

In vitro, we sought to determine whether Ruxo treatment could sensitize cells to the effect of Taxol, rather than deliver an additive or synergistic therapeutic effect on cell growth. A supra-physiologic concentration of Ruxo $(2.5-10 \mu \mathrm{M})$ was selected in order to explore this potential modulation of the therapeutic effect of Taxol $[26,27]$. We found that Ruxo did not exhibit anti- proliferative activity in ID8 or TOV-112D cells cultured in plates at any concentration used. We found that Ruxo in combination with low-dose Taxol reduced proliferation of murine ID8 and human TOV-112D ovarian cancer cells and that Ruxo did indeed significantly increase the sensitivity of cancer cells to the anti-proliferative effect of Taxol. Previous studies of human ovarian cancer cells describe Taxol induced expression of markers associated with cellular stress and stem cell phenotypes and that this induction can be limited by the JAK inhibitor CYT387 $[17,42]$. We hypothesized, from a mechanistic standpoint, that Ruxo inhibition of JAK $1 / 2$ may similarly limit Taxol induction of expression of markers associated with stress and stemness. In agreement with previous studies, we observed that treatment with a low concentration of Taxol was sufficient to increase the expression of stress/ stem markers GRP78, CD133, SCA-1, and CD117 in ID8 cells and that Ruxo significantly reduced the expression of GRP-78 and CD133, and modestly reduced SCA-1 and CD117 expression.

We then demonstrated that Ruxo limited the capacity of cells to form colonies in a soft agar assay, an in vitro measure thought to correlate strongly with tumorigenic potential [43]. Similar to our in vitro observations, cells pre-treated with Ruxo, Taxol, or the combination of the two agents, limited their capacity to initiate tumors in vivo in immune competent mice. The data from mice that received $2.5 \times 10^{5}$ cells demonstrate that pre-treatment with Ruxo or low-dose Taxol individually can reduce the capacity of cancer cells to form tumors, and that the combination of both treatments was most effective in this regard. Mice that received a larger number of cells (2.5 $\mathrm{x} 10^{6}$ ) also demonstrated reduced tumor growth, though the benefit of pre-treatment with Taxol or the combination of Ruxo and Taxol was nearly identical, a difference that may result from the larger number of cells injected. Taken together, these data indicate that JAK $1 / 2$ inhibitors, including Ruxo, can limit the expression of stress/stem markers by cancer cells induced by treatment with Taxol and thereby reduce tumorigenic potential suggesting that one mechanism of Ruxo sensitization to low-dose Taxol is mediated by the limitation of the capacity of cancer cells to adapt to stress.

Previous reports demonstrate that inhibition of JAK/STAT signaling reduces ovarian cancer growth in vitro and in an immunodeficient xenograft mouse model [17]. Here we explored the in vivo effects of Ruxo in an immune competent orthotopic syngeneic ovarian cancer model in light of the important role the immune system plays in the response to tumors. To understand the effect of low and high doses of Ruxo and their therapeutic effect in vivo, we evaluated Ruxo delivered either at a dose of $75 \mathrm{mg} / \mathrm{Kg} / \mathrm{d}$ (Ruxo 75) or a reduced dose of $30 \mathrm{mg} / \mathrm{Kg} / \mathrm{d}$ (Ruxo 30) to mitigate the potential for negative impact on anti-tumor immunity (equivalent to $\sim 5-10 \mathrm{mg}$ bid Ruxo in humans). Monotherapy with 
Ruxo 30 or Ruxo 75 did not significantly limit tumor growth, though both treatments did confer a moderate survival benefit. Treatment with Ruxo 75 in combination with a single Taxol 10 administration did reduce tumor growth, though it did not provide a statistically significant survival benefit. Conversely, the combination of Ruxo 30 and a Taxol 10 treatment limited tumor growth, increased median survival, and improved survival significantly as compared to control mice, Taxol monotherapy, or Ruxo treatment alone. One possible explanation for the improved performance of Taxol 10 in combination with Ruxo 30 as compared to Ruxo 75 may result from the reported capacity of both Taxol and Ruxo to influence immune function. Administration of $30 \mathrm{mg} / \mathrm{kg}$ once-perday in the murine system is analogous steady-state plasma drug concentrations to the lowest FDA-approved doses for this drug (5-10 mg BID, [35]) and may not interfere with adaptive anti-tumor immune function.

Taxol is reported to not only limit cancer cell division, but to also stimulate macrophages, TH1 T-cell responses, adjuvant immune responses to both tumor cell and defined antigens, and impair regulatory T-cell (Treg) function [38, 39, 44]. Moreover, low-dose administration of Taxol has been demonstrated to reduce T-reg and myeloid derived suppressor cell (MDSC) function, while enhancing both the number and interferon- $\Upsilon$ (IFN- $\Upsilon$ ) production of CD4 and CD8 T-cells within tumors [40]. Conversely, administration of Ruxo $75 \mathrm{mg} / \mathrm{Kg}$ to mice (which is akin to the highest FDA-approved doses for this agent; 20-25 mg BID) can limit DC activation and stimulation of antigen specific T-cell responses [35, 45]. Recently, Benci et al. reported that Ruxo treatment can disrupt JAK/STAT mediated chronic intra-tumoral interferon signaling and restore sensitivity to checkpoint blockade therapy [46]. The authors note that optimization of Ruxo dose and regimen would be essential, particularly considering the important role of interferon signaling in anti-tumor responses [46]. Our study confirms the importance of reduced dose Ruxo in combination with low dose taxol and serves as a focus for future exploration of the effect of this combinatorial therapeutic approach on anti-tumor immunity.

Ruxo is under evaluation as a potential therapy for solid tumors in several clinical trials. These trials utilize Ruxo doses ranging from $10 \mathrm{mg}$ daily to $25 \mathrm{mg}$ BID. Our data suggest that studies to evaluate the efficacy of Ruxo treatment for solid tumors, particularly in combination with chemotherapy and potentially low-dose Taxol, may observe improved responses through reduced dosing of Ruxo as opposed to the maximum tolerated dose or doses used to treat myeloproliferative disorders. Our study provides preclinical data demonstrating that treatment of ovarian cancer with Ruxo can sensitize cancer cells to chemotherapy, limit their stress/stem response, reduce tumor initiation and growth, and extend survival of tumorbearing mice. These data support further investigation into the application of this strategy to best benefit patients. Continued study of Ruxo in the context of syngeneic models will enable investigation of the impact of Ruxo and Taxol therapy on both tumor cell biology and immune cell function to inform the effective use of this drug combination in patients with ovarian cancer.

\section{MATERIALS AND METHODS}

\section{Cell lines}

ID8 cells, a clone of the MOSEC ovarian carcinoma (gift from Paul Terranova, Univ. of Kansas) and TOV112 D cells (ATCC CRL-11731), were cultured in DMEM supplemented with $10 \% \mathrm{FBS}, 1 \%$ L-glutamine, and $1 \%$ Penicillin/Streptomycin at $37^{\circ} \mathrm{C}$ and $5 \% \mathrm{CO}_{2}$. ID8-Luc cells were generated by transduction with MSCV-HygroLuc retrovirus and selected using $400 \mu \mathrm{g} / \mathrm{mL}$ Hygromycin for two weeks.

\section{Flow cytometry}

ID8 cells were seeded in 6-well plates $(500,000$ cells/well), incubated for $96 \mathrm{hr}$, and harvested using enzyme free Dissociation Buffer (Thermo Fisher Scientific 13151014). Equal numbers of cells from each condition were labeled with antibody by incubation at $4^{\circ} \mathrm{C}$ on a rocker. After washing, where needed, cells were incubated with secondary antibody for $45 \mathrm{~min}$, and washed twice prior to analysis. Labeled cells analyzed with a BD Fortessa and FlowJo software.

Antibodies: Anti-GRP78 (C-20) Santa Cruz Biotechnology. Anti-mouse Ly-6A/E (Sca-1) [D7], anti-CD133 [315-2C11], anti-CD117 (c-kit) [ACK2], anti-CD44 [IM7] from Biolegend, anti-goat alexa fluor conjugated antibody from Jackson ImmunoResearch.

\section{In vitro assays with Ruxo and Taxol}

Paclitaxel (Taxol) was purchased from Sigma Aldrich. Ruxolitinib (Ruxo) obtained from Medchemexpress and LC Labs. For proliferation assays, cells were cultured in 96-well black assay plates with optically clear bottoms, including a standard curve plate. Plates were incubated at $37^{\circ} \mathrm{C}$ with $5 \% \mathrm{CO} 2$, with all conditions in triplicate. In sequential delivery experiments (Figure 1C \& 1D) of small molecules and chemotherapy ID8 or TOV-112D cells were exposed to Ruxo in a 6 well plate $\left(2.5 \times 10^{5}\right.$ cells/well $)$ for 72 or $96 \mathrm{hr}$ respectively. Cells were harvested, washed in fresh media, and cell viability determined with propidium iodide, and cell suspension diluted to contain the desired number of viable cells. For each condition 500 viable ID8 cells or 2500 viable TOV-112D cells were then seeded into a 96-well plate. Cells were then incubated in DMEM containing carrier, Ruxo, Taxol, or both for $72 \mathrm{hr}$ (ID8) or $96 \mathrm{hr}$ (TOV- 
112D). Proliferation was measured using CyQuant Kit (Invitrogen) and read on a Perkin Elmer Envision 2103. Drugs were not replenished during any of the experiments. Data was analyzed in Graphpad Prism 7.

\section{Colony formation assay}

Agar stock was prepared in water for the top $(0.6 \%)$ and bottom (0.8\%) layers with SeaPlaque Agarose (Lonza, cat 50070). The agar and $2 \mathrm{X}$ DMEM was warmed in a $42{ }^{\circ} \mathrm{C}$ water bath for $30 \mathrm{~min}$ prior to mixing in equal proportions in a 24 -well plate, $0.5 \mathrm{~mL}$ of bottom agar was added, rocked to distribute agar, and allowed to solidify. During this time, ID8 cells were trypsinized in the hood and $4 \times 10^{4}$ cells per $\mathrm{mL}$ suspension was made. Cell suspensions were then mixed with soft agar stock in the $42^{\circ} \mathrm{C}$ water bath $(1: 2) .0 .5 \mathrm{~mL}$ of the cell/DMEM/ agar mixture then was added to each well. Drug-DMEM stocks were made to achieve the proper concentrations: Ruxo (25 and $10 \mu \mathrm{M})$, and Taxol $(0.015$ and $0.005 \mu \mathrm{M})$. The total volume of each well was $1.1 \mathrm{~mL}$. Plates were then incubated in a humidified incubator with $50 \% \mathrm{CO}_{2}$ for 20-30 days. At the end of the experiment, each well was stained with $0.005 \%$ crystal violet in $15 \%$ ethanol (140 $\mu \mathrm{L}$ per well) and plates were incubated again for several hours. Micrographs taken using an Olympus CK2 microscope coupled to an Omax A3550U camera. Colonies equal or bigger than $2 \mathrm{~mm}$ (ID8) or $5 \mathrm{~mm}$ (TOV112D) were counted with the ITCN plugin for Image J.

\section{In vivo tumor generation, imaging, and treatment}

Female C57BL/6 mice (6-8 week old) were obtained from Jackson Laboratories. All experiments were conducted in accordance with guidelines from the Public Health Service Policy on Humane Care of Laboratory Animals and were approved by the Institutional Animal Care and Use Committee of Massachusetts General Hospital under protocol 2008N000128. Mice were monitored daily for health and survival and were euthanized when recommended by staff veterinarians on the basis of signs of distress as determined by: hunched posture, decreased activity, increased respiratory rate, ruffled fur, and progressive ascites formation.

In all in vivo experiments, ID8-Luc cells were washed twice in phosphate-buffered saline (PBS), harvested with non-enzymatic disassociation buffer, collected by centrifugation at $400 \mathrm{~g}$ for $5 \mathrm{~min}$. Cells were passed over a $70 \mu \mathrm{m}$ filter, enumerated, and viability determined using propidium iodide, and cell concentration adjusted to inject $200 \mu \mathrm{L}$ of PBS containing viable ID8Luc intraperitoneally (IP) into female C57BL/6 mice.

Tumor-bearing mice were imaged once a week for 5 weeks with an IVIS imaging system. Mice were injected with $100 \mu \mathrm{L}$ D-luciferin Potassium Salt $(30 \mathrm{mg} / \mathrm{L}$, Regis Technologies) and after a $10 \mathrm{~min}$ incubation mice were imaged for 180 s to determine luciferase activity from ID8-Luc tumor cells. To quantify luciferase activity from tumors, an identical Region Of Interest (ROI) was created for each animal and the total flux/s (photons per second) was measured for each ROI.

\section{In vivo tumor initiation model}

ID8-Luc cells were cultured in vitro in the presence of Ruxo $10 \mu \mathrm{M}$, Taxol $5 \mathrm{nM}$, both Ruxo $10 \mu \mathrm{M}$ and Taxol $5 \mathrm{nM}$, or carrier (DMSO) for 48hrs, harvested, and viable cells enumerated to deliver $5 \times 10^{5}$ or $5 \times 10^{6}$ viable cells IP.

\section{Tumor growth and survival model}

Sub-confluent ID8-Luc cells were harvested as above to deliver $5 \times 10^{6}$ viable ID8-Luc cells to each mouse. Seven days post-injection mice tumor burdens were determined by imaging and mice were equally distributed across treatment groups. Ruxolitinib phosphate, either with $30 \mathrm{mg} / \mathrm{Kg}$ (Ruxo-Lo) or $75 \mathrm{mg} / \mathrm{Kg}$ (Ruxo-Hi), was delivered by oral gavage once daily A single Taxol treatment was performed by intraperitoneal injection of $0.2 \mathrm{mg}$ Taxol solution in $100 \mu \mathrm{L}$. Treatment schedules were as indicated in Figure 5.

\section{Statistical analysis}

All statistical analysis was conducted using Graphpad Prism 7. As indicated in figure legends, oneway or two-way ANOVA analyses were conducted followed by multiple comparisons with Bonferroni correction. Survival data was analyzed for median survival as well as individual survival curve comparisons to control conducted using Mantel-Cox test.

\section{Abbreviations}

BID - bis in die (twice per day); DMSO - dimethyl sulfoxide; EGFR - epidermal growth factor receptor; JAK - Janus Kinase; QD - quaque die (once per day); Ruxo - Ruxolitinib; STAT - signal transducer and activator of transcription; Taxol - Paclitaxel; T-reg - regulatory T-cell; VEGF - vascular endothelial growth factor

\section{Author contributions}

PMR, MAA, FRWK, KV, and XT conducted experiments. PMR, RFS, and MCP conceived of the study. PMR and MCP designed experiments and authored the manuscript. PMR, CG, RFS, and MCP provided data interpretation and authored the manuscript. 


\section{ACKNOWLEDGMENTS}

We would like to thank our colleagues at the Vaccine and Immunotherapy Center, Ruxandra Sirbulescu, Brian Garrison and Pankaj Mandal for helpful discussions. Many thanks to Valentine Comalis and Laura Libby for support on IVIS imaging.

\section{Declarations}

\section{Ethics approval and consent to participate}

Not applicable - all cells used are previously derived and publicly available without identifying information.

\section{Consent for publication}

Not applicable.

\section{Availability of data and material}

The datasets used and/or analyzed during the current study are available from the corresponding author on reasonable request.

\section{CONFLICTS OF INTEREST}

The authors have no competing to interests declare.

\section{FUNDING}

This project was supported by the Schinazi Fellowship (to PMR) and the Vaccine and Immunotherapy Center Innovation Fund. RFS is funded by NIH grant 2P30AI050409 and 1RO1MH100999. PR funded by the Prof. Ray Schinazi Research Fellowship Fund. MP DOD/ Congressionally Directed Medical Research Program W81XWH-13-PRCRP-IA. PR and MCP funded by the VIC Innovation Fund.

\section{REFERENCES}

1. Howlader N, Noone AM, Krapcho M, Miller D, Bishop K, Altekruse SF, Kosary CL, Yu M, Ruhl J, Tatalovich Z, Mariotto A, Lewis DR, Chen HS, et al. SEER Cancer Statistics Review, 1975-2013, National Cancer Institute. Bethesda, MD. 2016.

2. Siegel RL, Miller KD, Jemal A. Cancer statistics, 2015. CA Cancer J Clin. 2015; 65: 5-29. https://doi.org/10.3322/ caac. 21254.

3. Kigawa J. New strategy for overcoming resistance to chemotherapy of ovarian cancer. Yonago Acta Med. 2013; 56: 43-50.

4. Miyake TM, Sood AK, Coleman RL. Contemporary use of bevacizumab in ovarian cancer. Expert Opin Biol Ther. 2013; 13: 283-94. https://doi.org/10.1517/14712598.2012 .745508 .
5. Nishimura T, Nakamura K, Yamashita S, Ikeda S, Kigure $\mathrm{K}$, Minegishi T. Effect of the molecular targeted drug, erlotinib, against endometrial cancer expressing high levels of epidermal growth factor receptor. BMC Cancer. 2015; 15: 957. https://doi.org/10.1186/s12885-015-1975-5.

6. Sourbier C. Ovarian cancer: emerging molecular-targeted therapies. Biologics. 2012; 6: 147-54. https://doi. org/10.2147/BTT.S24155.

7. Scharer CD, Laycock N, Osunkoya AO, Logani S, McDonald JF, Benigno BB, Moreno CS. Aurora kinase inhibitors synergize with paclitaxel to induce apoptosis in ovarian cancer cells. J Transl Med. 2008; 6: 79. https://doi. org/10.1186/1479-5876-6-79.

8. Whicker ME, Lin ZP, Hanna R, Sartorelli AC, Ratner ES. MK-2206 sensitizes BRCA-deficient epithelial ovarian adenocarcinoma to cisplatin and olaparib. BMC Cancer. 2016; 16: 550. https://doi.org/10.1186/s12885-016-2598-1.

9. Putters J, da Silva Almeida AC, van Kerkhof P, van Rossum AG, Gracanin A, Strous GJ. Jak2 is a negative regulator of ubiquitin-dependent endocytosis of the growth hormone receptor. PLoS One. 2011; 6: e14676. https://doi. org/10.1371/journal.pone.0014676.

10. Scopelliti A, Cammareri P, Catalano V, Saladino V, Todaro M, Stassi G. Therapeutic implications of cancer initiating cells. Expert Opin Biol Ther. 2009; 9: 1005-16. https://doi. org/10.1517/14712590903066687.

11. Silva IA, Bai S, McLean K, Yang K, Griffith K, Ginestier C, Johnston C, Kueck A, Reynolds RK, Wicha MS, Buckanovich RJ, Thomas D. Aldehyde dehydrogenase in combination with CD133 defines angiogenic ovarian cancer stem cells that portend poor patient survival. Cancer Res. 2012; 71: 3991-4001. https://doi.org/10.1158/0008-5472. CAN-10-3175.Aldehyde.

12. Bourguignon LY, Peyrollier K, Xia W, Gilad E. Hyaluronan-CD44 interaction activates stem cell marker Nanog, Stat-3-mediated MDR1 gene expression, and ankyrin-regulated multidrug efflux in breast and ovarian tumor cells. J Biol Chem. 2008; 283: 17635-51. https://doi. org/10.1074/jbc.M800109200.

13. Lengyel E. Ovarian cancer development and metastasis. Am J Pathol. 2010; 177: 1053-64. https://doi.org/10.2353/ ajpath.2010.100105.

14. Mo L, Bachelder RE, Kennedy M, Chen PH, Chi JT, Berchuck A, Cianciolo G, Pizzo SV. Syngeneic murine ovarian cancer model reveals that ascites enriches for ovarian cancer stem-like cells expressing membrane GRP78. Mol Cancer Ther. 2015; 14: 747-56. https://doi. org/10.1158/1535-7163.MCT-14-0579.

15. Mittal S, Mifflin R, Powell DW. Cancer stem cells: the other face of Janus. Am J Med Sci. 2009; 338: 107-12. https://doi.org/10.1097/MAJ.0b013e3181ad5865.

16. Minn AJ, Wherry EJ. Combination cancer therapies with immune checkpoint blockade: convergence on interferon signaling. Cell. 2016; 165: 272-5. https://doi.org/10.1016/j. cell.2016.03.031. 
17. Abubaker K, Luwor RB, Zhu H, McNally O, Quinn MA, Burns CJ, Thompson EW, Findlay JK, Ahmed N. Inhibition of the JAK2/STAT3 pathway in ovarian cancer results in the loss of cancer stem cell-like characteristics and a reduced tumor burden. BMC Cancer. 2014; 14: 317. https://doi. org/10.1186/1471-2407-14-317.

18. Wilson GS, Tian A, Hebbard L, Duan W, George J, Li $\mathrm{X}$, Qiao L. Tumoricidal effects of the JAK inhibitor Ruxolitinib (INC424) on hepatocellular carcinoma in vitro. Cancer Lett. 2013; 341: 224-30. https://doi.org/10.1016/j. canlet.2013.08.009.

19. Wang TH, Chan YH, Chen CW, Kung WH, Lee YS, Wang ST, Chang TC, Wang HS. Paclitaxel (Taxol) upregulates expression of functional interleukin-6 in human ovarian cancer cells through multiple signaling pathways. Oncogene. 2006; 25: 4857-66. https://doi.org/10.1038/ sj.onc. 1209498 .

20. Gavegnano C, Detorio M, Montero C, Bosque A, Planelles V, Schinazi RF. Ruxolitinib and tofacitinib are potent and selective inhibitors of HIV-1 replication and virus reactivation in vitro. Antimicrob Agents Chemother. 2014; 58: 1977-86. https://doi.org/10.1128/AAC.02496-13.

21. Fridman JS, Scherle PA, Collins R, Burn TC, Li Y, Li J, Covington MB, Thomas B, Collier P, Favata MF, Wen X, Shi J, McGee R, et al. Selective inhibition of JAK1 and JAK2 is efficacious in rodent models of arthritis: preclinical characterization of INCB028050. J Immunol. 2010; 184: 5298-307. https://doi.org/10.4049/jimmunol.0902819.

22. Thomas SJ, Snowden JA, Zeidler MP, Danson SJ. The role of JAK/STAT signalling in the pathogenesis, prognosis and treatment of solid tumours. Br J Cancer. 2015; 113: 365-71. https://doi.org/10.1038/bjc.2015.233.

23. Chase A, Bryant C, Score J, Haferlach C, Grossmann V, Schwaab J, Hofmann WK, Reiter A, Cross NC. Ruxolitinib as potential targeted therapy for patients with JAK2 rearrangements. Haematologica. 2013; 98: 404-8. https:// doi.org/10.3324/haematol.2012.067959.

24. Hurwitz HI, Uppal N, Wagner SA, Bendell JC, Beck JT, Wade SM, Nemunaitis JJ, Stella PJ, Pipas JM, Wainberg ZA, Manges R, Garrett WM, Hunter DS, et al. Randomized, double-blind, phase II study of ruxolitinib or placebo in combination with capecitabine in patients with metastatic pancreatic cancer for whom therapy with gemcitabine has failed. J Clin Oncol. 2015; 33: 4039-47. https://doi. org/10.1200/JCO.2015.61.4578.

25. ClinicalTrials.gov. Ruxolitinib Phosphate, Paclitaxel, and Carboplatin in Treating Patients With Stage III-IV Epithelial Ovarian, Fallopian Tube, or Primary Peritoneal Cancer. March 15. 2016. Available from https://clinicaltrials.gov/ ct2/show/study/NCT02713386.

26. Chen X, Williams WV, Sandor V, Yeleswaram S. Population pharmacokinetic analysis of orally-administered ruxolitinib (INCB018424 Phosphate) in patients with primary myelofibrosis (PMF), post-polycythemia vera myelofibrosis
(PPV-MF) or post-essential thrombocythemia myelofibrosis (PET MF). J Clin Pharmacol. 2013; 53: 721-30. https://doi. org/10.1002/jcph.102.

27. Verstovsek S, Mesa RA, Gotlib J, Levy RS, Gupta V, DiPersio JF, Catalano JV, Deininger M, Miller C, Silver RT, Talpaz M, Winton EF, Harvey JH, et al. A double-blind, placebo-controlled trial of ruxolitinib for myelofibrosis. N Engl J Med. 2012; 366: 799-807. https://doi.org/10.1056/ NEJMoa1110557.

28. Rowinsky EK, Jiroutek M, Bonomi P, Johnson D, Baker SD. Paclitaxel steady-state plasma concentration as a determinant of disease outcome and toxicity in lung cancer patients treated with paclitaxel and cisplatin . Clin Cancer Res. 1999; 5: 767-74.

29. Jamis-Dow CA, Klecker RW, Sarosy G, Reed E, Collins JM. Steady-state plasma concentrations and effects of taxol for a $250 \mathrm{mg} / \mathrm{m} 2$ dose in combination with granulocytecolony stimulating factor in patients with ovarian cancer. Cancer Chemother Pharmacol. 1993; 33: 48-52. https://doi. org/10.1007/BF00686022.

30. Morton SW, Lee MJ, Deng ZJ, Dreaden EC, Siouve E, Shopsowitz KE, Shah NJ, Yaffe MB, Hammond PT. A nanoparticle-based combination chemotherapy delivery system for enhanced tumor killing by dynamic rewiring of signaling pathways. Sci Signal. 2014; 7: ra44. https://doi. org/10.1126/scisignal.2005261.

31. Lee MJ, Ye AS, Gardino AK, Heijink AM, Sorger PK, MacBeath G, Yaffe MB. Sequential application of anticancer drugs enhances cell death by rewiring apoptotic signaling networks. Cell. 2012; 149: 780-94. https://doi. org/10.1016/j.cell.2012.03.031.

32. Chen S, Forrester W, Lahav G. Schedule-dependent interaction between anticancer treatments. Science. 2016; 351: 1204-9. https://doi.org/10.1126/science.aac5610.

33. Sparreboom A, Wolff AC, Verweij J, Zabelina Y, Van Zomeren DM, McIntire GL, Swindell CS, Donehower $\mathrm{RC}$, Baker SD. Disposition of docosahexaenoic acidpaclitaxel, a novel taxane, in blood: In vitro and clinical pharmacokinetic studies. Clin Cancer Res. 2003; 9: 151-9.

34. Zhang X, Burt HM, Mangold G, Dexter D, Von Hoff D, Mayer L, Hunter WL. Anti-tumor efficacy and biodistribution of intravenous polymeric micellar paclitaxel. Anticancer Drugs. 1997; 8: 696-701. https://doi. org/10.1097/00001813-199708000-00008.

35. Haile WB, Gavegnano C, Tao S, Jiang Y, Schinazi RF, Tyor WR. The Janus kinase inhibitor ruxolitinib reduces HIV replication in human macrophages and ameliorates HIV encephalitis in a murine model. Neurobiol Dis. 2016; 92: 137-43. https://doi.org/10.1016/j.nbd.2016.02.007.

36. Hu Y, Hong Y, Xu Y, Liu P, Guo DH, Chen Y. Inhibition of the JAK/STAT pathway with ruxolitinib overcomes cisplatin resistance in non-small-cell lung cancer NSCLC. Apoptosis. 2014; 19: 1627-36. https://doi.org/10.1007/ s10495-014-1030-z. 
37. Bonner JA, Trummell HQ, Bonner AB, Willey CD, Bredel M, Yang ES. Enhancement of cetuximab-induced radiosensitization by JAK-1 inhibition. BMC Cancer. 2015; 15: 673. https://doi.org/10.1186/s12885-015-1679-x.

38. Machiels JP, Reilly RT, Emens LA, Ercolini AM, Lei RY, Weintraub D, Okoye FI, Jaffee EM. Cyclophosphamide, doxorubicin, and paclitaxel enhance the antitumor immune response of granulocyte/macrophage-colony stimulating factor-secreting whole-cell vaccines in HER-2/neu tolerized mice. Cancer Res. 2001; 61: 3689-97.

39. Javeed A, Ashraf M, Riaz A, Ghafoor A, Afzal S, Mukhtar MM. Paclitaxel and immune system. Eur J Pharm Sci. 2009; 38: 283-90. https://doi.org/10.1016/j.ejps.2009.08.009.

40. Landreneau JP, Shurin MR, Agassandian MV, Keskinov AA, Ma Y, Shurin G V. Immunological mechanisms of low and ultra-low dose cancer chemotherapy. Cancer Microenviron. 2013; 8: 57-64. https://doi.org/10.1007/ s12307-013-0141-3.

41. Shurin MR. Dual role of immunomodulation by anticancer chemotherapy. Nat Med. 2013; 19: 20-2. https://doi. org/10.1038/nm.3045.

42. Abubaker K, Latifi A, Luwor R, Nazaretian S, Zhu H, Quinn MA, Thompson EW, Findlay JK, Ahmed N. Shortterm single treatment of chemotherapy results in the enrichment of ovarian cancer stem cell-like cells leading to an increased tumor burden. Mol Cancer. 2013; 12: 24.

43. Montesano R, Drevon C, Kuroki T, Saint Vincent L, Handleman S, Sanford KK, DeFeo D, Weinstein IB. Test for malignant transformation of rat liver cells in culture: cytology, growth in soft agar, and production of plasminogen activator. J Natl Cancer Inst. 1977; 59: 1651-8.

44. Yuan L, Wu L, Chen J, Wu Q, Hu S. Paclitaxel acts as an adjuvant to promote both Th1 and Th2 immune responses induced by ovalbumin in mice. Vaccine. 2010; 28: 4402-10. https://doi.org/10.1016/j.vaccine.2010.04.046.

45. Heine A, Held SA, Daecke SN, Wallner S, Yajnanarayana SP, Kurts C, Wolf D, Brossart P, Andrea S, Held E, Daecke SN, Wallner S, Yajnanarayana SP, et al. The JAK-inhibitor ruxolitinib impairs dendritic cell function in vitro and in vivo. Blood. 2013; 122: 1192-202. https://doi.org/10.1182/ blood-2013-03-484642.

46. Benci JL, Xu B, Qiu Y, Wu TJ, Dada H, Twyman-Saint Victor C, Cucolo L, Lee DS, Pauken KE, Huang AC, Gangadhar TC, Amaravadi RK, Schuchter LM, et al. Tumor interferon signaling regulates a multigenic resistance program to immune checkpoint blockade. Cell. 2016; 167 : 1540-54. https://doi.org/10.1016/j.cell.2016.11.022. 